\title{
On the Social Validity of Behavior-Analytic Communication: a Call for Research and Description of One Method
}

\author{
Thomas S. Critchfield ${ }^{1}$ - Amel Becirevic ${ }^{2}$. \\ Derek D. Reed $^{2}$
}

Published online: 7 April 2017

(C) Association for Behavior Analysis International 2017

\begin{abstract}
It has often been suggested that nonexperts find the communication of behavior analysts to be viscerally off-putting. We argue that this concern should be the focus of systematic research rather than mere discussion, and describe five studies that illustrate how publicly available lists of word-emotion ratings can be used to estimate the responses of general-audience listeners. Our results provide support for the hypothesis that some of the ways in which behavior analysts tend to discuss their discipline can be unpleasant, but also illustrate inter- and intraindividual variations in pleasantness. Although our methods are atypical for behavior-analytic research, they are appropriate to the topic and sufficient to suggest many directions for additional research through which a field that considers itself sophisticated in matters of verbal behavior might shed light on its own disciplinary communication challenges.
\end{abstract}

Keywords Verbal behavior - Listener behavior Emotion · Positivity · Dissemination

\section{Introduction}

Behavior analysts go to great lengths to empirically evaluate the functions of stimuli and behaviors that interest them (e.g., Ferster \& Skinner, 1957; Iwata, Dorsey, Slifer, Bauman, \& Richman 1982; Sidman, 1960). A historically prominent exception to this rule has concerned the functions of behavior analysts' own discipline-specific verbal

The original version of this article was revised: The correct Family Name of the second author is Becirevic.

Thomas S. Critchfield

tscritc@ilstu.edu

1 Department of Psychology, Illinois State University, Normal, IL 61761, USA

2 University of Kansas, Lawrence, KS 66045, USA 
behavior. Behavior theory focuses heavily on precise description of behavioral phenomena, and the discussions it evokes seem so different from everyday talk (e.g., Skinner, 1945, 1953, 1957, 1977) that even some behavior analysts have admitted to speaking a distinct language or dialect (one that we call called "behaviorese," loosely following a precedent by Newman, Reeve, Reeve, \& Ryan, 2003). Over the years, numerous writers have expressed concern that whatever benefits are conferred by this "unnatural way of speaking" (Maurice, 1993, p. 88), in terms of precise communication among experts, may be at least partially outweighed by adverse effects of disciplinary jargon on nonexperts (e.g., Bailey, 1991; Berger, 1974; Doughty, Holloway, Shields, \& Kennedy, 2012; Foxx, 1996; Freedman, 2015; Lindsley, 1991; Normand, 2014; Poling, 2010; Schlinger, 2014; Smith, 2015; Todd \& Morris, 1993; Vyse, 2014).

Our present interest is in the possibility that the verbal behavior of behavior analysts may elicit undesirable "gut level" emotional responses in some listeners:

Words have the power to incite, comfort, inflame, sooth [sic], excite, calm, prejudice, and assuage. In effect, they set the occasion for behavior. In the case of behavior analysis, our words affect [behavior analysts'] image and ... ability to relate to others. (Foxx, 1996, p. 147)

It is noteworthy that some consumers reportedly invoke concepts like "abrasive" (Lindsley, 1991, p. 479) and "harsh" (Maurice, 1993, p. 102) when describing the verbal behavior of behavior analysts. Such reactions are narrative-independent (i.e., they do not necessarily concern the behavior analyst's literal "message"), and their potential importance in the applied realm should be obvious: "Consumers relate favorably to someone who is likeable and positive" (Foxx, 1996, p. 157). In short, people do not choose to spend time with those whose verbal behavior they regard as unpleasant, and clients are more likely to seek out, and follow the suggestions of, therapists with whom they feel socially comfortable (Backer, Liberman, \& Kuehnel, 1986; Barrett-Lennard, 1962; Rosenzweig, 1936). Presumably, the same applies to students, policy makers, and professional colleagues who are not behavior analysts (e.g., Berger, 1973).

If an emotional disconnect exists between behavior analysts and the nonexperts with whom they interact, it may, as both Foxx (1996) and Lindsley (1991) have alluded, result from a repurposing of everyday language to create technical terms (see also Dietz \& Arrington, 1983; Skiba \& Deno, 1991; Yulevich \& Axelrod, 1983). For example, Skinner, who coined much of the vocabulary of behavior analysis,

...Sometimes chose words that meant different things to other people than they did to him. He never checked what his technical words meant to most people. It was left for those of us who applied his free operant principles and methods to struggle with abrasive jargon ... which turned users away. (Lindsley, 1991, p. 449)

Thus, many of the words that behavior analysts employ so judiciously for precision of expression are verbal topographies that also participate in a wide variety of everyday functional relations. Because nonexperts have experienced these topographies in different contexts than scholarly discussion, technical terms can elicit emotional associations and occasion actions very different from what the expert speaker of "behaviorese" 
may anticipate. To the uninitiated, for instance, a conjunctive contingency sounds vaguely like an eye infection (conjunctivitis), and discrimination, as Foxx (1996) pointed out, is something that Civil Rights law has attempted to curtail. To suggest that such associations are "irrational" or reflect "misunderstandings" is to overlook their potential to disrupt productive relations between professionals and consumers.

To make matters worse, Lindsley (1991) suggested that the problem is not restricted to specialized technical terms. For instance, among the words that appear most frequently in Science and Human Behavior (Skinner, 1953) are problem (193 times) and variations of manipulate (93 times) and control (1040 times). These words are not especially offensive as scientists use them, but in everyday discourse, they may carry unpleasant connotations ${ }^{1}$ (Doughty et al., 2012). If so, then listeners may find linguistic traditions in behavior analysis to be off-putting even when stripped of disciplinespecific technical jargon.

\section{Using Published Word Corpora to Estimate Normative Emotional Responses}

Most often, concerns that "behaviorese" elicits unwanted emotional reactions in some listeners have been raised on the basis of casual observation (e.g., Bailey, 1991; Berger, 1973; Doughty et al., 2012; Foxx, 1996; Freedman, 2015; Lindsley, 1991; Normand, 2014; Poling, 2010; Schlinger, 2014; Smith, 2015; Todd \& Morris, 1993; Vyse, 2014). Although a few empirical studies support the existence of a "marketing problem" in behavior analysis (Becirevic, Critchfield, \& Reed, 2016; Jarmolowicz et al., 2008; Witt, Moe, Gutkin, \& Andrews, 1984), we are aware of no relevant program of sustained research. To evaluate the extent to which certain aspects of "behaviorese" really strike the nonexpert ear as unpleasant, we have explored the use of large, publicly available data sets (corpora) for evaluating the general pleasantness of verbal behavior as people outside of the behavior analysis community experience it (e.g., Critchfield, Becirevic, \& Reed, 2016; Critchfield et al., 2017). The words in these corpora have been rated by "listeners" for the extent to which they elicit emotional responses, and we will describe how the data sets can be employed to estimate two outcomes of interest: the normative degree to which specific behavior analysis terms, considered individually, may be perceived as unpleasant; and the overall emotional impact of large samples of individual verbal behavior.

Before proceeding to our analyses, we acknowledge that our general approach, in the context of Skinner's (1957) analysis of verbal behavior, may seem both familiar and strange. It should be familiar because, like Skinner, we eschew any notion that verbal behavior contains inherent "meaning"-verbal behavior participates in functional relations, and "meaning" is merely a convenient label for the sum of those relations. In our approach, we regard behavior-analytic communication as a source of antecedent stimuli, one function of which may be to elicit emotional responding in nonexperts. Here, we adopt the traditional view in behavior analysis that emotions are responses that may also function as motivating operations for other responses by the same

\footnotetext{
${ }^{1}$ Not our subjective impression. In a large data set of almost 14,000 English words ranked for levels of perceived pleasantness (Warriner, Kuperman, \& Brysbaert, 2013), problem (86th percentile), controlling (87th), and manipulate (90th) are among the most unpleasant.
} 
individual (for elaboration, see Skinner, 1953, 1957; for an updated account that is grounded in stimulus relations, see Friman, Hayes, \& Wilson, 1998).

Our approach may seem strange because of its focus on the word as a unit of analysis. Skinner (1957) clearly rejected the word - a unit of topography-as the foundation for analyzing verbal behavior: "Purely formal analyses ... are of little interest here, where no form of verbal behavior is significant apart from its controlling variables" (p. 331). However, stimulus control is heavily dependent on the properties of antecedent stimuli (Mostofsky, 1969), and in the present discussion, the stimuli that may control listener emotional responses are speaker verbal topographies that may be conveniently parsed into "words." 2 For present purposes, then, words are of interest precisely because they are a unit of topography with which nonexpert listeners have considerable prior experience. Because of this experience, listeners may respond to words simultaneously on many levels. For example, the title of the television series Schitt's Creek refers to a place named jointly for a person and a geographical feature, but when the title is displayed on screen, its orthographic and phonological properties mediate a certain scatological humor. To paraphrase the concerns of people like Lindsley (1991) and Foxx (1996), it is possible that many of the words that behavior analysts employ are problematic ("abrasive") partly because to nonexperts they look or sound angry, mean, uncaring, Machiavellian, etc.

Researchers create word-emotion corpora by presenting words, in isolation, to individual listeners, each of whom rates the emotional response that each word evokes. Each word is then characterized by aggregating (e.g., averaging) the ratings of many listeners. An obvious concern about this method is that listener behavior is examined at the group level ( $M$ ratings), whereas research in behavior analysis usually focuses on the behavior of individuals. We note, however, that discussion about a "marketing problem" in behavior analysis typically has described the effects of behaviorese on the "public"-which implies group-aggregate data as the proper level of analysis.

Another possible concern is whether listener responses to isolated words have any bearing on how listeners perceive larger samples of speaker verbal behavior. For instance, once a speaker strings words together to "tell a story," the resulting narrative might render gut-level emotional responses to individual words rather unimportant. Skinner (1957) suggested otherwise, noting that speaker behavior could elicit listener emotional responses ("these may include conditioned reflexes of the Pavlovian variety"; p. 357) that are independent of the speaker's putative message ("much of the emotional... behavior of the listener ... has little to do with grammar and syntax. An obscene word has its effect regardless of its location or grammar"; p. 344). More importantly, a large literature focusing on "sentiment analysis" assumes that the general emotional impact of words is an important adjunct to narrative relations (Baccianella, Esuli, \& Sebastiani, 2010; Bliss et al., 2012; Dodds, Harris, Kloumann, Bliss, \& Danforth, 2011; Pang \& Lee, 2008). In this literature, "sentiment" refers to an aggregate of all positive and negative emotional responses to the words in a sample of speaker

\footnotetext{
${ }^{2}$ Skinner was not above availing himself of this convenience. Before abandoning empirical work on the topic in favor of theoretical analysis in Verbal Behavior (1957), Skinner looked for orderly patterns in published samples of verbal behavior (e.g., Skinner 1934, 1941). In two studies, he focused on large lists of wordsspecifically, word associates that people emit upon hearing a target word (Cook \& Skinner, 1939; Skinner, 1937). We suggest that this is not very far afield from the present emphasis on narrative-independent emotional responses.
} 
behavior, and general impressions about communication tend to correlate with this aggregate (Avey, Avolio, \& Luthans, 2011; Floh, Koller, \& Zauner, 2013; GarciaMarques, Mackie, Claypool, \& Garcia-Marques, 2004; Petty, Schumann, Richman, \& Strathman, 1993). This suggests that emotion ratings of individual words provide a useful point of departure in evaluating a potential "marketing problem" in behavior analysis.

\section{General Method}

The corpora we examined were produced by Dodds et al. (2015; hereafter referred to as the "Dodds corpus") and Warriner, Kuperman, and Brysbaert (2013; hereafter referred to as the "Warriner corpus"). Here, in service of brevity, we describe only selected aspects of the methods employed in those studies; further details, along with instructions for downloading the data sets, may be found in the source articles.

The Dodds and Warriner corpora provide $M$ ratings, by presumably typical adults, for approximately 10,000 and 14,000 individual English ${ }^{3}$ words, respectively. We say "presumably typical" because, as is common in this kind of research, emotion ratings were obtained through large-scale survey technology. For instance, the Warriner corpus was created using the online crowdsourcing platform Amazon mTurk. Although the reports of Dodds et al. (2015) and Warriner et al. (2013) provide limited demographic information, ${ }^{4}$ there is evidence that in large-scale studies, mTurk workers tend to approximate US demographics reasonably well and to outperform college-based convenience samples in this regard (Paolacci \& Chandler, 2014). In both studies, words were rated on 9-point scales with anchors of "happy" and "unhappy" defining the end points. This is a common method for estimating the general pleasantness, or valence, of word connotations. In keeping with the practices of the relevant literature, we will refer to the ratings as ranging from negatively valenced (less than the scale midpoint) through neutral (midpoint $=5$ ) to positively valenced (greater than the midpoint).

Valence ratings, by design, are occasioned by simple verbal topographies rather than the narrative context of large samples of verbal behavior. That is, words are presented one at a time and raters are prompted to respond quickly so that each rating is a visceral first reaction (Warriner et al., 2013). This approach does not discount the possibility of narrative context transforming word function but rather seeks to record listener responses that may compete with or supplement the effects of a molar narrative. For each word, the Dodds and Warriner corpora provide $M$ ratings from between 18 and 50 unique raters who, of course, may have different verbal histories and thus may not respond identically to the same word. $M$ ratings thus carry the generic liabilities of

\footnotetext{
${ }^{3}$ Although our present focus is on English, investigations like those we describe here can be conducted for many other languages. For example, Dodds et al. (2015) provided corpora for 11 non-English languages (Arabic, French, German, Hindi, Indonesian, Korean, Mandarin Chinese, Pashto, Portuguese, Russian, and Urdu) and separately developed corpora that exist for such languages as Spanish (Stadthagen-Gonzales, Imbault, Perez Sanchez, \& Brysbaert, 2016), Polish (Riegel et al., 2015), Portuguese (Soares, Comesaña, Pinheiro, Simões, \& Frade, 2012), and German (Vo et al., 2009). Source articles indicate how to access these corpora.

${ }^{4}$ The Warriner et al. (2013) participants were a slight majority female, representing a broad range of ages and levels of education. Dodds et al. (2015) did not provide demographic information about their participants.
} 
aggregate data, including that they cannot be generalized to predict the behavior of any single listener. These data can, however, be assumed to provide a normative estimate of pleasant versus unpleasant listener reactions.

In the studies that follow, we employed the Dodds and Warriner corpora more or less interchangeably, with procedural specifics varying across studies (in part reflecting the evolution of our methods as the investigation unfolded). The practice of treating the corpora interchangeably can be defended on statistical grounds. Although the corpora were created using slightly different survey procedures and include nonidentical sets of words, Warriner and Kuperman (2015) found that their valence distributions were similar and that same-word ratings were strongly correlated. In as-yet unpublished work, Critchfield and Karla J. Doepke (2017) found that, for selected behavior analysis terms that were found in both corpora, pleasantness ratings correlated at $r=+0.93$. That said, for many purposes, we have found the Warriner corpus to be more useful because it contains more of the words that behavior analysts use frequently. The Dodds data set does offer the advantage of including corpora for several languages, thereby supporting inquiries into languages other than English.

\section{Study 1: Norms of Word-Emotion Valence}

The ultimate goal of our work is to estimate how "behaviorese" may be experienced by the nonexpert listener; however, any sample of verbal behavior must be evaluated in the context of normative practices of the verbal community. The core prediction of the "marketing problem" is that words of "behaviorese" are experienced more negatively than the norm. In study 1 , we attempt to summarize this norm.

In all natural languages that have been examined to date, positively valenced words have been found to outnumber, and to be employed more frequently, than negatively valenced words. This pattern, referred to as a positivity bias, was first described by Boucher and Osgood (1969) and has been frequently replicated. For example, Dodds et al. (2015) sampled about 10,000 words from each of 12 languages and, in all cases, found that a majority of words were positively valenced (see also Critchfield et al., 2016). Yet to say that, for instance, $71 \%$ of English words were positively rated ignores considerable interword variance. In study 2 and study 3 , we describe an economical way to summarize the overall range of valences in a sample of words. In study 4 and study 5 , we use a variant of this method to characterize the "behaviorese" of some individual behavior analysts.

Some theoretical accounts portray positivity bias as an audience effect in which speakers (who coin and use words) are sensitive to the fact that listeners tend to respond favorably to positively valenced words (e.g., Warriner \& Kuperman, 2015). However, it is thought that speakers may favor negatively valenced words when they "intend" to convey strong emotional intensity (e.g., Norris, Larsen, Crawford, \& Cacioppo, 2011; Rozin \& Royzman, 2001; Warriner \& Kuperman, 2015), as when tacting danger or manding in situations of conflict. The prediction is that positivity dominance should weaken or disappear as the magnitude of emotional valence increases, and our own analysis of valence distributions for 12 languages published by Dodds et al. (2015, see Figure 1 in the original article) suggests that this is in fact the case (Critchfield et al., 2016). To illustrate, our Fig. 1 (left panel) compares the numbers of English words that 


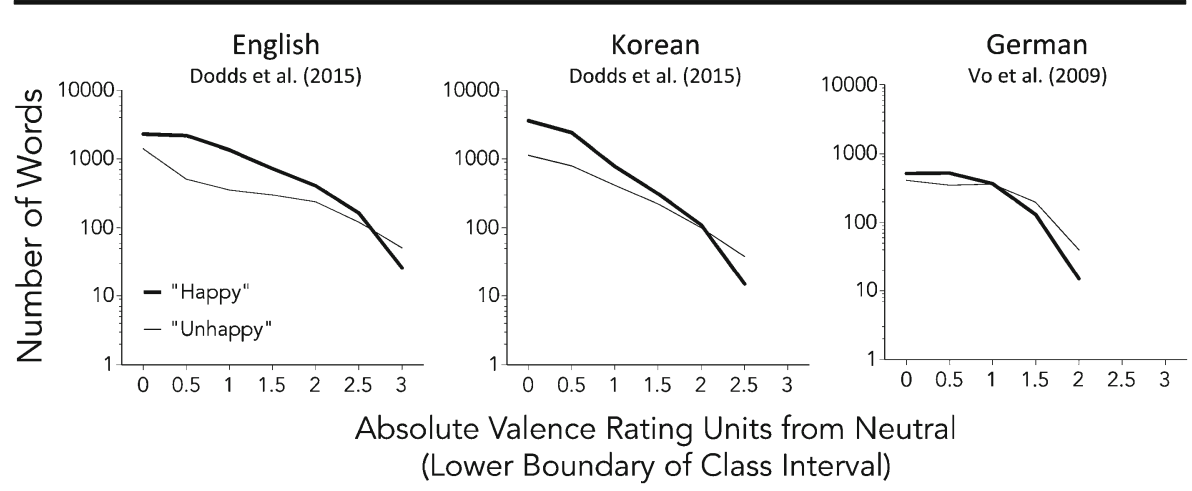

Fig. 1 Study 1: number of "Happy" versus "Unhappy" words, as a function of valence intensity, in large corpora representing three languages. See text for explanation

were rated as "Happy" (rating $>5$ on the 9-point scale described previously) and "Unhappy" (rating <5) in the Dodds corpus as a function of the intensity of the valence rating (i.e., how far from neutral on the rating scale). Note that positive words predominate except at the most extreme level of valence intensity (right side of each panel). Figure 1 (middle and right panels) shows that this pattern holds for other languages, in this case the Dodds Korean corpus and a corpus of 2902 German words described by Vo et al. (2009). It holds as well for other English corpora like that of Warriner (Critchfield et al., 2016).

For present purposes, Fig. 1 illustrates that, in all languages that have been studied to date, a majority of words evoke positive emotional responses. Therefore, this would be the expected outcome for a random sample of English words. If the vocabulary of "behaviorese" evokes mainly negative emotional responses, as the purported "marketing problem" suggests, then this would represent a clear deviation from same-language norms.

\section{Study 2: Empirically Derived Valences of Some Behavior-Analytic Terms}

In study 2, we used word-emotion ratings that were summarized in study 1 (Fig. 1, left panel) to gain a preliminary estimate of how nonexpert listeners may perceive the vocabulary of "behaviorese." Our sample of "behaviorese" came from Skinner's (1953) iconic Science and Human Behavior, which is considered an essential resource for any serious student of behavior analysis (e.g., Critchfield, Buskist, Saville, Sherburne, \& Crockett, 2000).

\section{Method}

We converted a pdf of Science and Human Behavior to a text file using the online utility pdftotext.com and examined the text file (titles, publisher information, table of contents, and references deleted) using the software Word Counter®, which produced a list of over 8000 unique words that appeared in Skinner's book. These were sorted from highest to lowest frequency of appearance in the book, and those occurring at a rate of at least 10 per 10,000 words were examined manually to extract a list of common 
behavior analysis technical terms. By this, we mean words that, in expert behavior analysis communication, are frequently employed and have unique meanings (i.e., different from lay use). At the risk of immodesty, we assumed that we were competent to make these judgments, but Fig. 2 shows the terms and readers may draw independent conclusions about their appropriateness. We treated variations on the same term (e.g., reinforce, reinforcement, reinforced) as one word when determining frequency of use. The technical terms then were compared with the Warriner et al. (2013) corpus of emotion ratings. Note that ratings could not be assigned for 5 of 26 terms because they do not appear in the corpus.

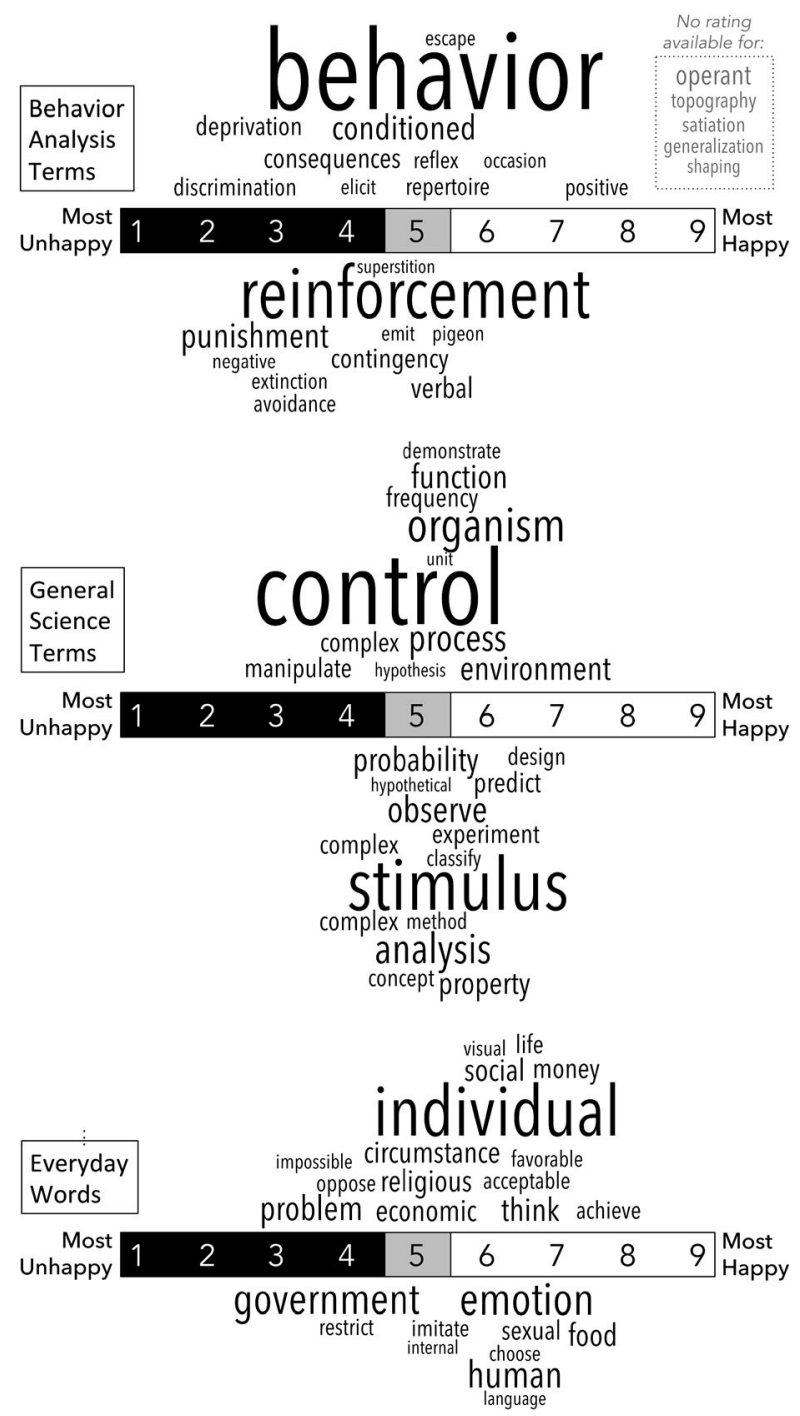

Fig. 2 Study 2: three types of words that appear frequently in Skinner's (1953) Science and Human Behavior, each positioned above its mean valence rating on a scale of $1=$ "Unhappy" to $9=$ "Happy." Size of font reflects relative frequency of occurrence. See text for further details 


\section{Results and Discussion}

In Fig. 2 (top panel), the horizontal axis shows the range of possible valences, and each technical term is shown, centered above its mean rating, in font size proportional to its frequency of use in Science and Human Behavior. In general, the ratings are consistent with concerns about a behavior analysis "marketing problem." Ratings tend to cluster to the left of the scale midpoint, implying mostly negative valences ("unhappy" connotations). Terms to which objections have been expressed previously (e.g., by Foxx, 1996) tend to be negatively rated (e.g., punishment $=2.76$; extinction $=3.1$ ). Not every detail of the ratings fits preconceptions, however. For example, Bailey (1991) suggested that behavior has negative connotations, but its Warriner corpus rating is 5.28 , which is essentially neutral on the valence scale. Reflex and conditioned, which might be presumed to have aversive associations to mindless or coercive behavior control, were similarly rated.

Several contexts aid in the interpretation of Fig. 2. First, it is possible that behavioranalytic terms are perceived negatively but not uniquely so in the context of professional communication (perhaps the language of science is generally unpleasant to the nonspecialist ear). To find out, we extracted from the high-frequency words in Science and Human Behavior terms that we recognized as generic to science but not peculiar to behavior analysis. During this process, we relied on what we regarded as common sense, and then cross-referenced our selections against several general-knowledge resources (such as high school science textbooks and an online encyclopedia of science: http://www.daviddarling.info/encyclopedia/ETEmain.html). From the resulting list, we randomly selected the 25 words shown in Fig. 2 (middle panel), for which valence ratings were available in the Warriner et al. (2013) corpus. As Bailey (1991) and Lindsley (1991) predicted, selected science terms have negative valences (e.g., control $=4.43$ and manipulate $=3.21$ ). Yet many of the science terms cluster a bit above the scale midpoint (64\% positive valences). Thus, although the general science terms can hardly be classified as joyful, neither are their valences systematically negative as tended to be the case with behavior analysis terms.

Second, as noted in the discussion of study 1 , a given sample of verbal behavior may be compared with normative practices of the verbal community. Figure 1 shows that a majority of English words are positively valenced, so we examined emotion ratings for some "everyday words" in Science and Human Behavior. By this, we mean words that Skinner employed approximately as they are used in lay discourse. From the most frequently appearing words in Science of Human Behavior that were not behavior analysis terms or general science terms, we deleted "noncontent" words (is, a, the, about, which, because, etc.) and then randomly selected 25 words for which a rating could be assigned from the Warriner corpus. Figure 2 (bottom panel) summarizes the results. Amidst considerable interword variation, a majority (80\%) of these everyday words are positively valenced as per the English-language norm.

Third, it has been suggested that the overall emotional impact of communication on a listener is affected disproportionately by the most strongly valenced words (e.g., Dodds \& Danforth, 2009). For example, when evaluating large samples of printed text, Reagan, Tivnan, Williams, Danforth, and Dobbs (2015) focused mainly on words that were rated below 4 and above 6 on the aforementioned 9-point "Happy" scale. Applying this heuristic to our sample of terms in Fig. 1, the ratio of strongly pleasant 
to strongly unpleasant behavior analysis terms was $2: 7$, compared to $3: 1$ for the general science terms and 14:4 for the everyday words.

We cannot say how representative Science and Human Behavior may be of Skinner's communication overall, or how representative Skinner may be of behavior analysts overall. We also cannot guarantee that the 76 words whose valence ratings we summarized are representative of anyone's overall word-use patterns. What can be said, however, is that Fig. 2 is consistent with the worry that "behaviorese" may be experienced by nonexpert listeners as unpleasant. The figure also indicates that the "marketing problem" may have two separate components: general science words that are perceived less positively than everyday words, and behavior analysis technical terms that are perceived more negatively. Finally, the figure includes a promising detail: Skinner (1953), when not relying on behavior analysis and general science terms, employed a preponderance of "happy" words that is consistent with English usage overall. This finding runs counter to our earlier proposal that nonmentalistic words might be generically aversive to the nonspecialist ear, and provides hope that even the most hard-bitten of behavior-analytic linguistic purists might possess skills that are adaptable to communicating with nonexperts.

\section{Study 3: A Methodological Note on Quantifying Overall Communication Valence}

To be clear, study 2 describes emotion ratings of particular words that are part of "behaviorese." It is another thing entirely to evaluate the general communication pattern of an individual speaker, which will necessarily include a variety of words reflecting different emotional valences. This implies the need to focus on distributions of word valences, as per study 1. However, the distributions shown in Fig. 1 incorporate a possible confound. Normatively speaking, speakers of different languages show different degrees of overall positivity bias. For instance, Dodds et al. (2015) found that, across 12 languages, the percentage of words that were positively valenced (rating $>5$ on the 9-point "Happy" scale) varied considerable across languages-for instance, $71 \%$ for English and 94\% for Hindi. This finding could imply that Hindi is a "happier" language than English, but as Critchfield et al. (2016) pointed out, it could instead reflect differences on how Hindi-speaking and English-speaking listeners use the rating scale. That is, the functional scale center, or the point at which valence is perceptually neutral, could differ across cultural and linguistic groups. Thus, by defining positivity by reference to the nominal scale center, past researchers may have entangled two separate factors: the actual degree to which listeners experience words as positive, and a nonstandard measurement frame of reference in categorizing words as positive. Only the former is interesting for present purposes.

The confound can be addressed by normalizing valence intensity, specifically by measuring valence in terms of relative rather than absolute deviation from the nominal scale center. In Fig. 2 (bottom row), this is done by treating the obtained mean rating in a corpus as the functional scale center and comparing the rating assigned to each word to this value. Because the variance of ratings differs across corpora, deviation from the center is expressed in standard deviation units of each corpus. Figure 3 shows the global effects of this 


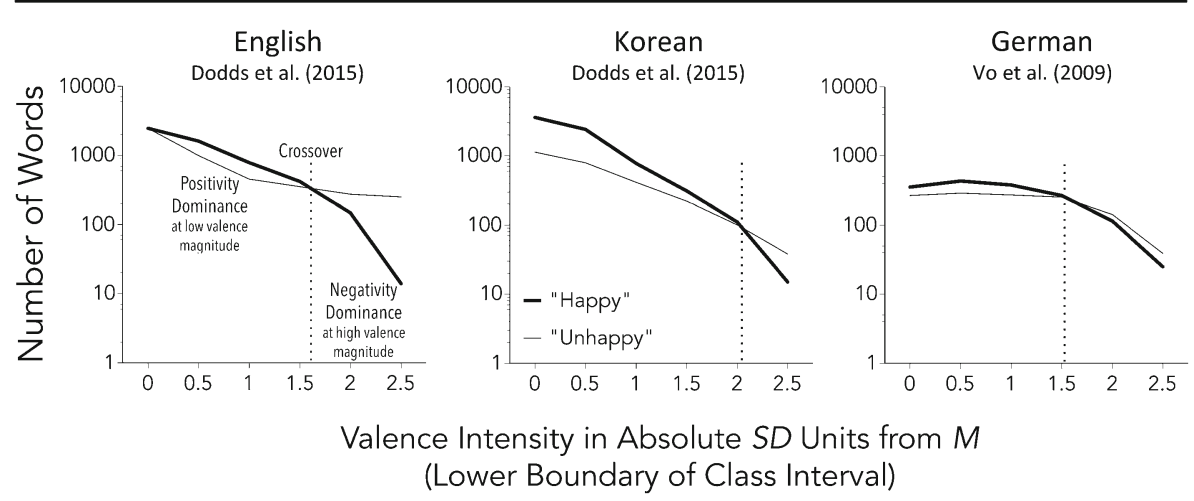

Fig. 3 Study 3: effects of normalizing on the ratio of positive ("Happy") to negative ("Unhappy") words in corpora representing several languages. See text for explanation

transformation by presenting the ratio of positively to negatively valenced words for several languages. Gray bars show untransformed ratios (rating $>5$ / rating $<5$ ), which vary considerably across languages (despite being studied in exactly the same way; data from Dodds et al., 2015). Black bars show transformed ratios (rating $>$ mean/rating $<$ mean). In all cases, the transformed ratios indicate more positive than negative words but are much more similar across languages. Critchfield et al. (2016) argued that, although the possibility that different language communities use rating scales differently remains a matter of speculation, ${ }^{5}$ normalizing represents a conservative approach that eliminates any possible influence of a rating-scale bias.

Figure 4 shows the specific effects of the transformation on valence distributions of the Dodds English and Korean corpora and the Vo German corpus. These normalized valence functions can be compared in two ways. First, because in all languages positivity appears to decrease with valence intensity, in each panel, a dashed line demarcates a "crossover point," a level of valence intensity at which positivity dominance gives way to negativity dominance (dashed lines). The higher the abscissa value at which crossover occurs, the more positive overall is a sample of words. Thus, the Dodds English corpus and the Vo German corpus look similar in this regard, and the Dodds Korean corpus appears more positive than either of them. Second, the portions of each panel to the left and right of the crossover point, respectively, show the relative degree of positivity dominance for low valence-intensity words and of negativity dominance for high valence-intensity words. When different samples contain approximately the same number of words, they can be compared in terms of the degree of separation of positive-word and negative-word functions on each side of the crossover point. Note that the Dodds Korean corpus shows enhanced positivity dominance at low valence magnitudes (left side) and the Dodds English corpus shows enhanced negativity dominance at high valence magnitudes (right side). We now demonstrate how this analysis can be applied to the verbal behavior of individuals.

\footnotetext{
${ }^{5}$ Moreover, Warriner and Kuperman (2015) have argued that, within the methods normally employed in word-emotion research, there may exist no reliable means of verifying whether such a rating scale bias really exists.
} 


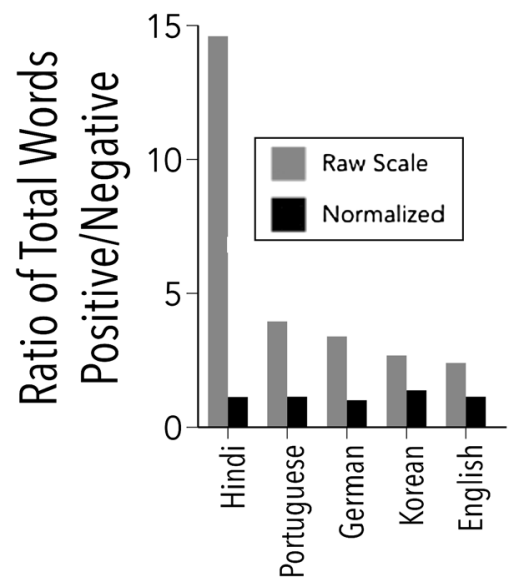

Fig. 4 Study 3: normalized word-valence functions for three languages. See text for explanation

\section{Study 4: Individual Speakers-a Behaviorist and a Humanist Comment on the "Control of Human Behavior"}

Mainstream scholars assume that, within a same-language verbal community, individual speakers will differ considerably in positivity (e.g., Norris et al., 2011). Consistent with this perspective, in study 4 , we used the normalized valence functions that were introduced in study 3 to compare levels of word-emotion positivity in samples of verbal behavior from two English-speaking psychologists. Specifically, we compare samples of text that were authored by B.F. Skinner and Carl Rogers for a "print symposium" in Science (Rogers \& Skinner, 1956). This is an interesting comparison because Skinner is regarded as the prototypical behaviorist, while Rogers, a humanistic psychologist, is remembered for his optimistic appraisal of human nature (e.g., he is regarded as a seminal influence to Positive Psychology; Seligman \& Csikszentmihalyi, 2000), for his strong clinical skills, and for his notions about human agency and the importance of feelings. Rogers thus may be the sort of foil Maurice (1993) had in mind when observing that, in public perception, behavior analysts play "Attila the Hun" (p. 283) to their competitors' "angel of love" (p. 283). ${ }^{6}$

\section{Method}

We converted a pdf copy of the article of Rogers and Skinner (1956) to text using the online utility pdftotext.com and deleted the references. From the resulting text files, we extracted the first of two sections authored by Skinner and the single section authored by Rogers and used WordCounter® to obtain lists of words used, and each word's frequency of use, in these selections. Before further analysis, proper nouns, dates and numbers, and words less than four characters in length were removed from the lists. The remaining words then were assigned valence ratings by comparing them to the

\footnotetext{
${ }^{6}$ Rogers' potentially relevant self-assessment: "I am a person who affirms more than criticizes" (quoted in Kirschenbaum \& Henderson, 1989, p. 119). 
Dodds corpus; when no rating was available, we consulted the Warriner corpus as well.

${ }^{7}$ Ratings were obtained for about $97 \%$ of words in the samples, or approximately 1000 unique words per author (see Table 1).

\section{Results and Discussion}

Figure 5 uses normalized valence functions to summarize results for Skinner and Rogers. The functions of both individuals roughly approximate what has been reported for the English language generally (e.g., Figure 2 of Dodds et al., 2015). That is, in both cases, positivity bias is evident for when valence intensity is low, and negativity bias is evident for when valence intensity is high. However, Skinner's text qualifies as more negative than Rogers' in three respects. First, Skinner shows less positivity dominance at low valence intensities than does Rogers. Second, Skinner's crossover occurs at a lower level of valence intensity than does that of Rogers. Third, Skinner shows more negativity dominance at high valence intensities than does Rogers. We suggest that, collectively, these patterns reflect precisely what would be expected of a behavior analyst with the language-based "marketing problem" that has been so often remarked upon by behavior analysts themselves (e.g., Bailey, 1991; Foxx, 1996; Lindsley, 1991).

\section{Study 5: Individual Speakers-Four Behavior Analysts Comment on Education}

So as not to pick on Skinner exclusively, or to imply that his style of communication represents that of all behavior analysts in all circumstances, we used the methods of study 4 to compare writing samples from four behavior analysts, all on the topic of education. Discussions of education have potential appeal to the general public, and as a result of this audience control, we speculated that the topic might occasion "happier" communication than the heavily philosophical exchange between Rogers and Skinner (1956). In selecting sources of text, obvious touchstones were Skinner's (1958) "Teaching machines," along with articles by two individuals who, in our experience, were regarded as pleasant communicators: Fred S. Keller (1968, "Goodbye, Teacher....") and Ogden Lindsley (1992, "Precision Teaching: Discoveries and Effects"). We added a selection by one of our favorite contemporary pleasant communicators, Janet S. Twyman (1998, "The Fred S. Keller School"). Although the sources are not perfectly comparable (e.g., they appeared in different journals and were authored at different times), they all are discussion articles rather than primary empirical reports, and they all contain some anecdotal material that might be expected to lend positivity to word selection.

\footnotetext{
${ }^{7}$ We consulted both corpora to maximize the number of words for which ratings were available (a word that is found in the Dodds corpus may not be found in the Warriner corpus, and vice versa). Using the Dodds corpus as primary was, at the time the research was conducted, an arbitrary decision. We have since found that the Warriner corpus is more likely to contain a given word of interest to behavior analysts. In future work of this type, we would therefore use the Warriner corpus as primary. Note that if a word was found in both corpora, the Dodds rating was used.
} 
Table 1 Studies 4 and 5: sources of word samples. See text for further explanation

\begin{tabular}{lclllll}
\hline Source & $\begin{array}{l}\text { Grade } \\
\text { level }^{\mathrm{a}}\end{array}$ & $\begin{array}{l}\text { Lexical } \\
\text { density }^{\mathrm{b}}\end{array}$ & $\begin{array}{l}\text { Ease of } \\
\text { listening }^{\mathrm{c}}\end{array}$ & $\begin{array}{l}\text { Total words } \\
\text { rated }^{\mathrm{d}}\end{array}$ & $\begin{array}{l}\text { Unique } \\
\text { words rated }\end{array}$ & $\begin{array}{l}\text { \% unrated } \\
\text { unique words }\end{array}$ \\
$\begin{array}{l}\text { Study 4 } \\
\quad \text { Skinner (Rogers \& } \\
\quad \text { Skinner, 1956) }\end{array}$ & 12.6 & 30 & 14 & 2295 & 1089 & 3.1 \\
$\quad \begin{array}{l}\text { Rogers (Rogers \& } \\
\quad \text { Skinner, 1956) }\end{array}$ & 12.9 & 21 & 16 & 3191 & 1039 & 3.0 \\
$\begin{array}{l}\text { Study 5 } \\
\text { Skinner (1958) }\end{array}$ & 9.7 & 33 & 10 & 1134 & 556 & 3.1 \\
$\quad$ Keller (1968) & 13.5 & 35 & 16 & 1206 & 632 & 3.0 \\
$\quad$ Lindsley (1992) & 11.8 & 35 & 13 & 1183 & 545 & 3.7 \\
$\quad$ Twyman (1998) & 14.5 & 36 & 18 & 1360 & 687 & 2.9 \\
\hline
\end{tabular}

${ }^{a}$ Flesch-Kincaid formula expresses reading difficulty as approximate US grade-level equivalent (Kincaid, Fishburne, Rogers, \& Chisholm, 1975)

b Based on the proportion of total words that are "content words" (i.e., nouns, verbs, etc.). Score is thought to correlate positively with reading difficulty (Halliday, 1985)

${ }^{\mathrm{c}}$ Fang Easy Listening formula: lower scores suggest greater ease of comprehension when text is read aloud (Fang, 1966)

${ }^{\mathrm{d}}$ After removing numbers, dates, proper names, and words of fewer than four characters

\section{Method}

Our samples consisted of the entire Twyman article, approximately the first 1500 words of the Keller and Lindsley articles, and approximately 1500 words of the Skinner article beginning on the second page with the section entitled, "Another Kind of Machine" (due to technical difficulties, we could not successfully scan and convert the article's first page). We created text files using the same procedure as in study 4 and, after removing unwanted content (proper nouns, dates and numbers, and words less than four characters in length), were left with approximately 1200 words per sample (Table 1) that were indexed to valence ratings in the Dodds and Warriner corpora.

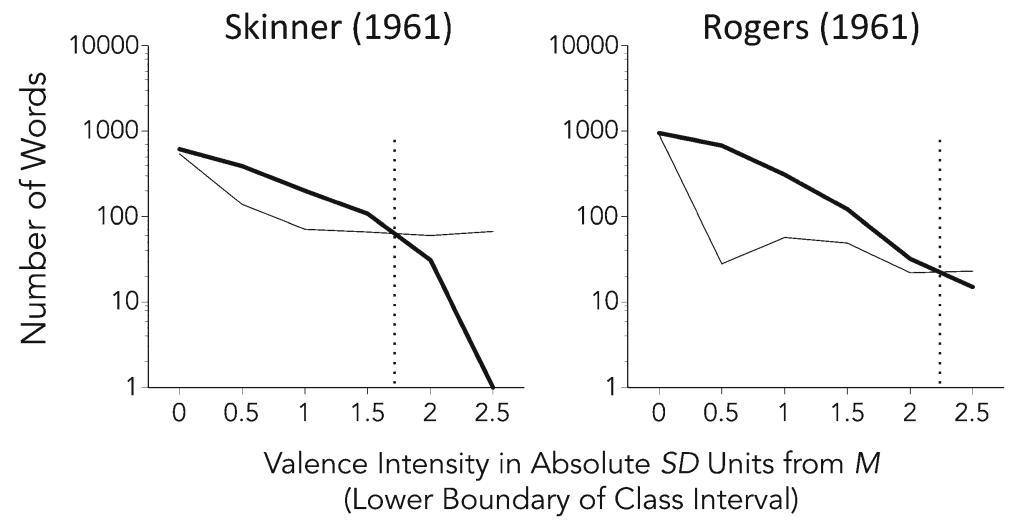

Fig. 5 Study 4: number of "Happy" and "Unhappy" words authored by B.F. Skinner and Carl R. Rogers in a joint publication 


\section{Results and Discussion}

Figure 6 shows normalized valence functions for the four target authors. As in study 4, these individual functions approximate what has been described for the English language generally (Dodds et al., 2015; see Fig. 2). As expected based on the type of articles we selected, the functions show evidence of greater overall positivity than Skinner exhibited in the Rogers and Skinner (1956) Science article of study 4. For all authors, note the pronounced separation between positive and negative word counts at lower levels of valence intensity, and compare to the results for Skinner [1961] in Fig. 3). To compare authors in terms of general positivity, the crossover measure (dashed lines) provides a convenient metric. In this regard, Lindsley and Keller both appear more positive than Skinner, and Twyman registers as the most positive of all. This finding suggests that it may be possible to express a behavior-analytic perspective on a single topic with varying degrees of positivity.

\section{General Discussion}

The present report demonstrates (a) that, at the level of a large corpus reflecting a substantial sample of words from a given language, emotional responses to words are distributed in an orderly way, with the majority of words evoking positive responses

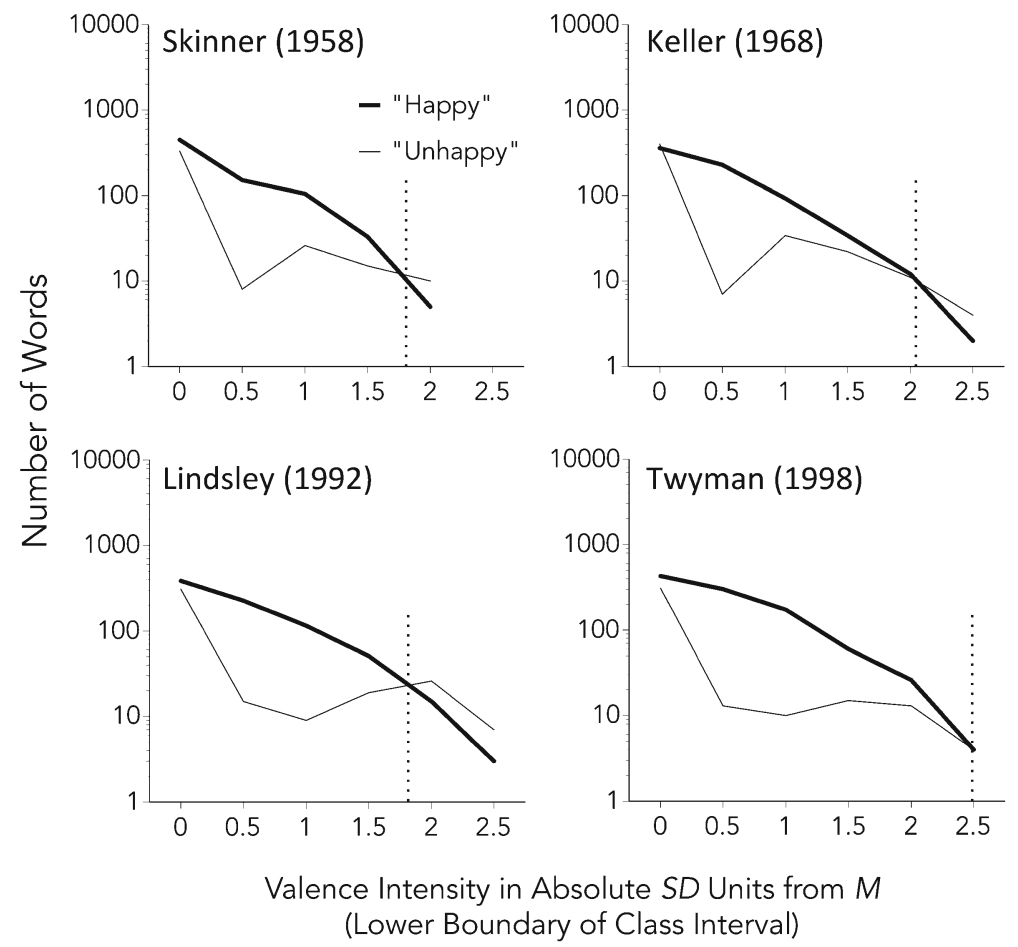

Fig. 6 Study 5: number of "Happy" and "Unhappy" words appearing in text samples extracted from articles on education by four behavior analysts 
(study 1); (b) that at least some behavior analysis terms appear to evoke negative emotional responses (study 2); and (c) that it is possible to use word-emotion ratings (normalized functions described in study 3 ) as a standard for evaluating the communication of individuals (studies 4 and 5).

We have therefore shown that an empirical basis may exist for concerns about a "marketing problem" in behavior analysis. Although empirical evidence that nonexperts react adversely to "behaviorese" is not unprecedented, it is also not the focus of most discussions about the field's possible "marketing problem." Moreover, most efforts at empirically characterizing a "marketing problem" in behavior analysis have been one-offs rather than part of a systematic research program (Becirevic et al., 2016; Jarmolowicz et al., 2008; Witt et al., 1984). We propose that publicly available corpora of word-emotion ratings provide one basis for creating such a systematic program. Below we describe three possible directions for future research.

One strategy is to examine emotional responses to "behaviorese" by members of different types of individuals. The methods of word-emotion studies (e.g., Dodds et al., 2015; Warriner et al., 2013) in effect treat "the general public" as a homogeneous group, whereas common sense suggests the existence of many subcommunities. For example, emotional responding to behavior analysis terms could differ for teachers versus parents, for members of different disciplines or professions (e.g., educators versus employees of business organizations), for persons affiliated with different cultural groups, for people who have and have not had some college instruction about behavior principles, and so forth. Existing word corpora do not address these distinctions, but the methods of word-emotion research are easily replicated and could therefore be applied to any subcommunity of interest. The results of audiencespecific studies should be more informative than the present report to professions who work with those subcommunities.

A second use for word-emotion ratings is to guide the development of written and spoken communications that are likely to be perceived pleasantly. Behavior analysts of all types interact with nonexperts (such as clients, students, colleagues who are expert in some other field), so it makes sense to be strategic about this challenge. For individual behavior analysts, we suggest drafting a section of text and then examining word-emotion corpora to reduce reliance on potential problem words (those with strong negative valences). Of course, not all words on which a behavior analyst might rely have been rated for valence (see Fig. 2), so researchers would need to obtain new ratings to guide such a process.

Relatedly, word-emotion ratings provide a way to empirically test claims of superiority for substitute terms. Several authors (e.g., Bailey, 1991; Foxx, 1996; Lindsley, 1991) have suggested ways to avoid "behaviorese" when communicating with nonexperts, but we are aware of no objective evidence that these alternative strategies are less "abrasive" than the jargon they are meant to replace (e.g., Critchfield et al., 2017). Research is needed to determine normative ratings of pleasantness for substitute terms.

A third, and especially valuable, direction for research is to determine the conditions under which emotional responses to "behaviorese" actually bear on the extent to which listeners will seek out, "like," and work collaboratively with the behavior analysts. The hypothesis that listeners will seek out pleasant communicators is not our own but rather has been "crowd sourced" over the years by many presumably qualified observers of application and scholarly collaboration (e.g., Bailey, 1991; Berger, 1974; Doughty 
et al., 2012; Foxx, 1996; Freedman, 2015; Lindsley, 1991; Normand, 2014; Poling, 2010; Schlinger, 2014; Smith, 2015; Todd \& Morris, 1993; Vyse, 2014). Moreover, it has been widely assumed that subjective (i.e., emotional) features of communication contribute to consumer embrace of quack therapies that compete with behavior analysis for human services market share (e.g., Green, 1996; Maurice, 1993; Shute, 2010). Nevertheless, these assumptions demand testing.

A few studies have asked potential consumers for verbal predictions of how they might react to an intervention that was described in "behaviorese" versus everyday language (e.g., Becirevic et al., 2016; Witt et al., 1994). However, behavior analysts have been cautioned to be wary of the predictive validity of verbal responses. As Baer, Wolf, and Risley (1968) colorfully observed, an individual's

...Verbal description of his own non-verbal behavior usually would not be accepted as a measure of his actual behavior.... Hence there is little applied value in the demonstration that an impotent man can be made to say that he is no longer impotent. The relevant question is not what he can say, but what he can do. (p.

93)

In this sense, our preliminary investigation of emotional responding to "behaviorese" falls short of demonstrating practical relevance. To do so, one would need to verify that people who respond negatively to "behaviorese" show reduced probability of seeking, accepting, or implementing behavior-analytic services. We suggest that the challenge of demonstrating such predictiveness is the same that must be confronted in social validity assessment, in which, following an intervention, consumers are asked to provide verbal reports of "treatment acceptability." These reports typically are taken as face-valid indicators of whether consumers will seek out similar services and recommend them to acquaintances in the future (e.g., Wolf, 1978), but data relevant to this assumption almost always are lacking (Carr, Austin, Britton, Kellum, \& Bailey, 1999). Ultimately, the understanding and remediation of the "marketing problem" in behavior analysis demands an analysis of the publicly observable actions people take after encountering "behaviorese." take time to accumulate, provisional insights, such as those afforded by word-emotion ratings, may have to suffice.

\section{Postscript: Marketing Is a Relative Phenomenon}

In the study of listener emotional responding to words, an implied goal is to determine how pleasant a speaker's verbal behavior must be in order to encourage various kinds of listener actions (or at least not to interfere with those actions). The critical variable may be how the aggregate valence of a speaker's verbal behavior compares to general norms of communication. Consider the general science terms that were presented in Fig. 2. Emotion ratings of most of these terms are nominally neutral, that is, near the rating-scale center. Yet against the backdrop of predominantly pleasant English words (recall that the majority of words are rated as "happy"), most of the general science terms qualify as relatively unpleasant. Similarly, the ratings of many behavior analysis

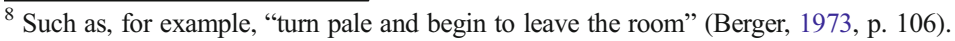


terms are not terribly far from the scale center. In examining this finding, our initial thought was that the "marketing problem" might not be as bad as past commentators had led us to believe. Yet upon reflection, it became clear that many of the terms evoke more negative listener responses than the majority of English words. Although it is tempting to imagine a fixed standard by which communication could be judged as "pleasant enough," we propose that listeners will judge a speaker's verbal behavior by comparison to the verbal behavior that they are accustomed to encountering. This may be true in the broad context of an overall verbal community and - recalling the concern that purveyors of quack therapies will "outsell" behavior analysts (Green, 1996; Maurice, 1993; Shute, 2010)—also in proximal comparisons between individual speakers.

To distill the essence of this proposition, imagine an experiment (Fig. 7) in which there is one listener and two speakers. The speakers, who are situated in soundattenuating booths, utter a single word every few seconds in no particular narratively defined order. The listener can press a lever to open a channel through which either speaker (but only one at a time) may be heard. The listener writes down the words that are heard, and later, if certain of these words have been recorded, they earn money for the listener. Because speakers say "money words" at equal rates, the listener should not prefer either of them on this basis (responding on the two levers should be roughly equal). In this instance, pleasantness, defined in terms of emotion ratings like those in the Dodds and Warriner corpora, could tip the balance of preference. Imagine that one speaker's words are, on the whole, more pleasant than the other's. According to the broad framework of the matching law, relative pleasantness should add to or detract from effects created by the base rates of "useful statements" (for discussions of how complex combinations of consequences fit into matching, see Critchfield et al., 2003; Killeen, 1972; McCarthy \& Davison, 1988).

The perspective of a human-services consumer is similar to that of the listener in our hypothetical experiment, in that the function of attending to a given speaker potentially is modulated by the speaker's communication style. A major difference concerns the time frame in which reinforcement follows attending. In the experiment, listening to a given speaker produces money fairly soon afterward. For a consumer of human services, however, the benefits of listening to behavior analysts can be quite delayed

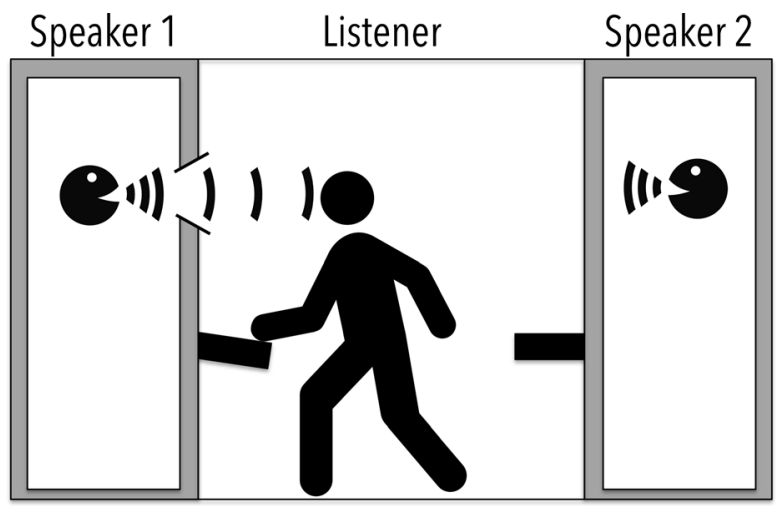

Fig. 7 A hypothetical experiment in which a listener's attention may be divided between two speakers as a function of the pleasantness of the words they speak. See text for explanation 
(e.g., it takes time to put behavioral programs into place and create socially important behavior change). Principles of delay discounting (e.g., Critchfield \& Kollins, 2001) predict, therefore, that these benefits will exert a weak influence over listener behavior, at least at first. Within this reinforcement vacuum, stylistic features of speaker verbal behavior may loom large when behavior analysts first communicate with consumers, and problems would be anticipated if the style is unpleasant. For example, Maurice (1993) provided a must-read case study of how easily one consumer's attention was diverted by more pleasant purveyors of alternative therapies.

To our knowledge, no experiment precisely like the one described above has been published, but there are intriguing parallels with a modest line of research in which a speaker directs communication to two or more listeners (Borrero et al., 2007; Conger \& Killeen, 1974; Pierce, Epling, \& Greer, 1981). The listeners differ in terms of the rate at which they deliver "statements of agreement" that are presumed to function as reinforcers. ${ }^{9}$ Consistent with the matching law (Davison \& McCarthy, 1988), allocation of speaker behavior to different listeners has tracked the relative occurrence of agreement statements. For present purposes, the interest is in specific verbal topographies that comprise agreement statements, about which the published reports unfortunately say little. Pierce et al. did not indicate what counted as a statement of agreement, while Borrero et al. and Conger and Killeen, respectively, provided only the examples of "I think you are right" (p. 593) and "Good" (p. 404). While it is plausible that social endorsement per se functions as a reinforcer, we note that good and right are among the more pleasant English words in the Warriner corpus ( $M$ rating of 7.89 and 7.32 , respectively, on the 9-point valence scale). The same is true of other words that might be used to express agreement, including correct (6.94), agree (7.17), and concur (6.00); see also true (7.08), amen (6.02), okay (6.56), and yes (6.74) in the Dodds corpus. It is possible, therefore, that agreement statements functioned as reinforcers partly because they employed words that people tend to perceive as pleasant, in which case the speaker in the published experiments functioned very much like the listener in our hypothetical experiment. On this basis, we suggest that results of the relevant studies might have been very different had agreement statements from one source taken the somewhat unpleasant form of "That's not totally stupid" or "Only an idiot would disagree." 10

Within the framework that we are proposing, there is no single criterion for how often a speaker (whether in an experiment or the everyday world) would have to utter pleasant words in order to be preferred. In our hypothetical experiment, speaker 1 should be preferred if she is frequently pleasant while speaker 2 is only occasionally so, occasionally pleasant while speaker 2 is occasionally unpleasant, or occasionally unpleasant while speaker 2 is frequently so. In matching, consequence effects always are relative to concurrently available alternatives. This highlights the importance of

\footnotetext{
${ }^{9}$ McDowell and Caron (2010a, b) employed a similar procedure except that approval statements from a single listener followed different kinds of speaker responses at different rates. Relative frequency of those two kinds of responses was well described by the matching law. The published reports did not, however, specify the specific topographies comprising approval statements.

${ }^{10}$ It is intriguing to note that one participant in Pierce et al. (1981) showed inverse matching (i.e., negative slope, indicating preference for the listener who made fewer "statements of agreement"). Although the relevant data are not available, we are tempted to suggest that variations in verbal topographies of the agreement statements, and corresponding emotional effects on the participant, might account for this curiosity.
} 
examining not just the stylistic features of behavior-analytic communication but also in the spirit of our Skinner-Rogers comparison, how the "competition" communicates as well (e.g., Shute, 2010).

Compliance with Ethical Standards This article does not contain any studies with human participants performed by any of the authors. It drew instead on archival, public-domain data sets. Therefore, institutional review board oversight does not apply.

Conflict of Interest The authors declare that they have no conflicts of interest.

Informed Consent Because the research used archival, public-domain data sets, conventions of informed consent do not apply.

\section{References}

Avey, J., Avolio, B. J., \& Luthans, F. (2011). Experimentally analyzing the impact of leader positivity on follower positivity and performance. The Leadership Quarterly, 22, 282-294. doi:10.1016/j. leaqua.2011.02.004.

Baccianella, S., Esuli, A., \& Sebastiani, F. (2010, May). SentiWordNet 3.0: an enhanced lexical resource for sentiment analysis and opinion mining. LREC, 10, 2200-2204.

Backer, T. E., Liberman, R. P., \& Kuehnel, T. G. (1986). Dissemination and adoption of innovative psychosocial interventions. Consulting and Clinical Psychology, 54, 111-118. doi:10.1037/0022-006 x.54.1.111.

Baer, D.M., Wolf, M.M., \& Risley, T.R. (1968). Some current dimensions of applied behavior analysis. Journal of Applied Behavior Analysis, 1, 91-97. doi:10.1901/jaba.1968.1-91

Bailey, J. S. (1991). Marketing behavior analysis requires different talk. Journal of Applied Behavior Analysis, 24, 445-448. doi:10.1901/jaba.1991.24-445.

Barrett-Lennard, G. T. (1962). Dimensions of therapist response as causal factors in therapeutic change. Psychological Monographs: General and Applied, 76, 1-36. doi:10.1037/h0093918.

Becirevic, A., Critchfield, T. S., \& Reed, D. D. (2016). On the social acceptability of behavior-analytic terms: crowdsourced comparisons of lay and technical language. The Behavior Analyst, 39(2), 305-317. doi:10.1007/s40614-016-0067-4.

Berger, M. (1973). Behaviorism in twenty-five words. Social Work, 18, 106-108.

Bliss, C.A., Kloumann, I.M., Harris, K.D., Danforth, C.M., \& Dodds, P.S. (2012). Twitter reciprocal reply networks exhibit assortativity with respect to happiness. Journal of Computational Science, 3, 388-397.

Borrero, J. C., Crisolo, S. S., Tu, Q., Rieland, W. A., Ross, N. A., Francisco, M. T., et al. (2007). An application of the matching law to social dynamics. Journal of Applied Behavior Analysis, 40, 589-601. doi:10.1901/jaba.2007.589-601.

Boucher, J., \& Osgood, C. E. (1969). The Pollyanna hypothesis. Journal of Verbal Learning and Verbal Behavior, 8, 1-8. doi:10.1016/s0022-5371(69)80002-2.

Carr, J. E., Austin, J. L., Britton, L. N., Kellum, K. K., \& Bailey, J. S. (1999). As assessment of social validity trends in applied behavior analysis. Behavioral Interventions, 14, 223-231. doi:10.1002/(sici)1099-078 x(199910/12)14:4<223::aid-bin37>3.0.co;2-y.

Conger, R., \& Killeen, P. (1974). Use of concurrent operants in small group research: a demonstration. Pacific Sociological Review, 17, 399-416. doi:10.2307/1388548.

Cook, S. W., \& Skinner, B. F. (1939). Some factors influencing the distribution of associated words. The Psychological Record, 3, 178-184.

Critchfield, T. S., Becirevic, A., \& Reed, D. D. (2016). In Skinner's early footsteps: analyzing verbal behavior in large public corpora. The Psychological Record. doi:10.1007/s40732-016-0197-9.

Critchfield, T. S., Buskist, W. F., Saville, B., Crockett, J., Sherburne, T., \& Keel, K. (2000). Sources cited most frequently in the experimental analysis of human behavior. The Behavior Analyst, 23, 255-266.

Critchfield, T.S., Doepke, K.J., Epting, L.K., Becirevic, A., Reed, D.D., Fienup, D.M., Kremsreiter, J.L., \& Ecott, C.L. (2017). Normative emotional responses to behavior analysis jargon, or, how not to use words to win friends and influence people. Behavior Analysis in Practice. doi:10.1007/s40617-016-0161-9 
Critchfield, T. S., \& Kollins, S. H. (2001). Temporal discounting: basic research and the analysis of sociallyimportant behavior. Journal of Applied Behavior Analysis, 34, 101-122. doi:10.1901/jaba.2001.34-101.

Critchfield, T. S., Paletz, E. M., MacAleese, K. R., \& Newland, M. C. (2003). Punishment in human choice: direct or competitive suppression? Journal of the Experimental Analysis of Behavior, 80, 1-27. doi:10.1901/jeab.2003.80-1.

Davison, M., \& McCarthy, D. (1988). The matching law: a research review. Englewood Cliffs, NJ: Erlbaum.

Dietz, S. M., \& Arrington, R. L. (1983). Factors confusing language use in the analysis of behavior. Behavior, 11, 117-132.

Dodds, P. S., Harris, K. D., Kloumann, I. M., Bliss, C. A., \& Danforth, C. M. (2011). Temporal patterns of happiness and information in a global social network: hedonometrics and Twitter. PloS One, 6(12), e26752. doi:10.1371/journal.pone.0026752.

Dodds, P. S., Clark, E. M., Desu, S., Frank, M. R., Reagan, A. J., \& Williams, J. R. (2015). Human language reveals a universal positivity bias. Proceedings of the National Academy of Sciences, 112, 2389-2394. doi:10.1073/pnas.1411678112.

Doughty, A. H., Holloway, C., Shields, M. C., \& Kennedy, L. E. (2012). Marketing behavior analysis requires (really) different talk: a critique of Kohn (2005) and a(nother) call to arms. Behavior and Social Issues, 21, 115-134. doi:10.5210/bsi.v21i0.3914.

Fang, I.E. (1966). The easy listening formula. Journal of Broadcasting \& Electronic Media, 11, 63-68.

Ferster, C. B., \& Skinner, B. F. (1957). Schedules of reinforcement. New York: Appleton-Century-Crofts.

Floh, A., Koller, M., \& Zauner, A. (2013). Taking a deeper look at online reviews: asymmetric effect of valence intensity on shopping behavior. Journal of Marketing Management, 29, 646670. doi:10.1080/0267257x.2013.776620.

Foxx, R. M. (1996). Translating the covenant: the behavior analyst as ambassador and translator. The Behavior Analyst, 19, 147-161.

Freedman, D. H. (2015). Improving the public perception of behavior analysis. The Behavior Analyst, 1-7. doi:10.1007/s40614-015-0045-2.

Friman, P. C., Hayes, P. C., \& Wilson, K. G. (1998). Why behavior analysts should study emotion: the example of anxiety. The Behavior Analyst, 31, 137-156. doi:10.1901/jaba.1998.31-137.

Garcia-Marques, T., Mackie, D. M., Claypool, H. M., \& Garcia-Marques, L. (2004). Positivity can cue familiarity. Personality and Social Psychology Bulletin, 30, 585-593. doi:10.1177/0146167203262856.

Green, G. (1996). Evaluating claims about treatments for autism. In C. Maurice, G. Green, \& S. C. Luce (Eds.), Behavioral intervention for young children with autism: a manual for parents and professionals (pp. 15-28). Austin, TX: Pro-Ed.

Halliday, M. A. K. (1985). Spoken and written language. Oxford: Oxford University Press.

Iwata, B. A., Dorsey, M. F., Slifer, K. J., Bauman, K. E., \& Richman, G. S. (1982). Toward a functional analysis of self-injury. Analysis and Intervention in Developmental Disabilities, 2, 320. doi:10.1016/0270-4684(82)90003-9.

Jarmolowicz, J. P., Kahng, A., Invarsson, E. T., Goysovich, R., Heggemeyer, R., \& Gregory, M. K. (2008). Effects of conversational versus technical language on treatment preference and integrity. Intellectual and Developmental Disabilities, 46, 190-199. doi:10.1352/2008.46:190-199.

Keller, F. S. (1968). Good-bye, teacher.... Journal of Applied Behavior Analysis, 1, 79-89. doi:10.1901/jaba.1968.1-79.

Kincaid, J.P., Fishburne, R.P., Rogers, R.L., \& Chisholm, B.S. (1975). Derivation of new readability formulas (automated readability index, fog count, and Flesch reading ease formula) for Navy enlisted personnel. Research Branch Report 8-75. Chief of Naval Technical Training: Naval Air Station Memphis.

Kirschenbaum, H., \& Henderson, V. L. (1989). Carl Rogers: dialogues-conversations with Martin Buber, Paul Tillich, B.F. Skinner, Gregory Bateson, Michael Polanyi, Rollo May, and others. Boston: HoughtonMifflin.

Lindsley, O. R. (1991). From technical jargon to plain English for application. Journal of Applied Behavior Analysis, 24, 449-458. doi:10.1901/jaba.1991.24-449.

Lindsley, O. R. (1992). Precision teaching: discoveries and effects. Journal of Applied Behavior Analysis, 25, 51-57. doi:10.1901/jaba.1992.25-51.

Maurice, C. (1993). Let me hear your voice: a family's triumph over autism. New York: Random House.

McDowell, J. J., \& Caron, M. L. (2010b). Matching in an undisturbed natural human environment. Journal of the Experimental Analysis of Behavior, 93, 415-433. doi:10.1901/jeab.2010.93-415.

McDowell, J. J., \& Caron, M. L. (2010a). Bias and undermatching in delinquent boys' verbal behavior as a function of their level of deviance. Journal of the Experimental Analysis of Behavior, 93, 471-483. doi:10.1901/jeab.2010.93-471.

Mostofsky, D. I. (1965). Stimulus generalization. Palo Alto, CA: Stanford University Press. 
Newman, B., Reeve, K. F., Reeve, S. A., \& Ryan, C. S. (2003). Behaviorspeak: glossary of terms in applied behavior analysis (ABA). Custer, WA: Dove and Orca.

Normand, M. P. (2014). Opening Skinner's box: an introduction. The Behavior Analyst, 37, 67-68. doi:10.1007/s40614-014-0016-Z.

Norris, C. J., Larsen, J. T., Crawford, E., \& Cacioppo, J. T. (2011). Better (or worse) for some than others: individual differences in the positivity offset and negativity bias. Journal of Research in Personality, 45, 100-111. doi:10.1016/j.jrp.2010.12.001.

Pang, B., \& Lee, L. (2008). Opinion mining and sentiment analysis. Foundations and Trends in Information Retrieval, 2, 1-135. doi:10.1561/1500000011.

Paolacci, G., \& Chandler, J. (2014). Inside the Turk: understanding mechanical Turk as a participant pool. Current Directions in Psychological Science, 23, 184-188. doi:10.1177/0963721414531598.

Petty, R. E., Schumann, D. W., Richman, S. S., \& Strathman, A. J. (1993). Positive mood and persuasion: different roles for affect under high- and low-elaboration conditions. Journal of Personality and Social Psychology, 64, 5-20. doi:10.1037/0022-3514.64.1.5.

Pierce, W. D., Epling, W. F., \& Greer, S. M. (1981). Human communication and the matching law. In C. M. Bradshaw, E. Szabadi, \& C. F. Lowe (Eds.), Quantification of steady-state operant behavior (pp. 345348). Amsterdam: Elsevier/North Holland.

Poling, A. (2010). Looking to the future: will behavior analysis survive and prosper? The Behavior Analyst, 33, 7-17.

Reagan, A., Tivnan, B.M. Williams, J.R., Danforth, C.M., \& Dobbs, P.S. (2015). Benchmarking sentiment analysis methods for large-scale texts: a case for using continuum-scored words and word-shift graphs.

Riegel, M., Wierzba, M., Wypych, M., Zurawski, L., Jednorog, K., Grabowska, A., \& Marchewka, A. (2015). Nencki Affective Word List (NAWL): cultural adaptation of the Berlin Affective Word List-Reloaded (BAWL-R) for Polish. Behavior Research Methods, 47, 1222-1236. doi:10.3758/s13428-014-0552-1.

Rogers, C. R., \& Skinner, B. F. (1956). Some issues concerning the control of human behavior: a symposium. Science, 124, 1057-1066. doi:10.1126/science.124.3231.1057.

Rosenzweig, S. (1936). Some implicit common factors in diverse methods of psychotherapy. American Journal of Orthopsychiatry, 6, 412-415. doi:10.1111/j.1939-0025.1936.tb05248.x.

Rozin, P., \& Royzman, E. B. (2001). Negativity bias, negativity dominance, and contagion. Personality and Social Psychology Review, 5, 296-320. doi:10.1207/s15327957pspr0504_2.

Schlinger, H. D. (2014). Publishing outside the box: unforeseen dividends of talking to strangers. The Behavior Analyst, 37, 77-81. doi:10.1007/s40614-014-0010-5.

Seligman, M. E. P., \& Csikszentmihalyi, M. (2000). Positive psychology: an introduction. American Psychologist, 55, 5-14. doi:10.1037//0003-066x.55.1.5.

Shute, N. (2010). Desperate for an autism cure. Scientific American, 303(4), 80-85. doi:10.1038/ scientificamerican1010-80.

Sidman, M. (1960). Tactics of scientific research. New York: Basic Books.

Smith, J. M. (2015). Strategies to position behavior analysis as the contemporary science of what works in behavior change. The Behavior Analyst, 1-13. doi:10.1007/s40614-015-0044-3.

Skiba, R. J., \& Deno, S. L. (1991). Terminology and behavior reduction: the case against "punishment.". Exceptional Children, 57, 298-313.

Skinner, B. F. (1934). Has Gertrude Stein a secret? Atlantic Monthly, 153(January), 50-57.

Skinner, B. F. (1937). The distribution of associated words. The Psychological Record, 1, 71-76.

Skinner, B. F. (1941). A quantitative estimate of certain types of sound-patterning in poetry. American Journal of Psychology, 54, 64-79. doi:10.2307/1417793.

Skinner, B. F. (1945). The operational analysis of psychological terms. Psychological Review, 52, $270-277$. doi: $10.1037 / \mathrm{h} 0062535$.

Skinner, B. F. (1953). Science and human behavior. New York: Macmillan.

Skinner, B. F. (1957). Verbal behavior. Englewood Cliffs, NJ: Prentice-Hall.

Skinner, B. F. (1958). Teaching machines. Science, 128, 969-977.

Skinner, B. F. (1977). About behaviorism. New York: Vintage.

Soares, A. P., Comesaña, M., Pinheiro, A. P., Simões, A., \& Frade, C. S. (2012). The adaptation of the Affective Norms for English words (ANEW) for European Portuguese. Behavior Research Methods, 44, 256-269. doi:10.3758/s13428-011-0131-7.

Stadthagen-Gonzalez, H., Imbault, C., Perez Sanchez, M.A., \& Brysbaert, M. (2016). Norms of valence and arousal for 14,031 Spanish words. Behavior Research Methods. Online prepublication; downloaded from http://link.springer.com/article/10.3758\%2Fs13428-015-0700-2. doi:10.3758/s13428-015-0700-2.

Todd, J. T., \& Morris, E. K. (1983). Misconception and miseducation: presentations of radical behaviorism in psychology textbooks. The Behavior Analyst, 6, 153-160. 
Twyman, J. S. (1998). The Fred S. Keller School. Journal of Applied Behavior Analysis, 31, 695-701. doi:10.1901/jaba.1998.31-695.

Vo, M. L.-H., Conrad, M., Kuckinke, L., Urton, K., Hofmann, M. J., \& Jacobs, A. M. (2009). The Berlin Affective Word List Reloaded (BAWL-R). Behavior Research Methods, 41, 534-538. doi: $10.3758 / \mathrm{brm} .41 .2 .534$.

Vyse, S. (2014). Publishing outside the box: popular press books. The Behavior Analyst, 37, 69-72. doi:10.1007/s40614-014-0013-2.

Warriner, A. B., \& Kuperman, V. (2015). Affective biases in English are bi-dimensional. Cognition and Emotion, 29, 1147-1167. doi:10.1080/02699931.2014.968098.

Warriner, A. B., Kuperman, V., \& Brysbaert, M. (2013). Norms of valence, arousal, and dominance for 13,915 English lemmas. Behavior Research Methods, 45, 1-17. doi:10.3758/s13428-012-0314-x.

Witt, J. C., Moe, G., Gutkin, T. B., \& Andrews, L. (1984). The effect of saying the same thing in different ways: the problem of language and jargon in school-based consultation. Journal of School Psychology, 22, 361-367. doi:10.1016/0022-4405(84)90023-2.

Wolf, M. M. (1978). Social validity: the case for subjective measurement or how applied behavior analysis is finding its heart. Journal of Applied Behavior Analysis, 11, 203-214. doi:10.1901/jaba.1978.11-203.

Yulevich, L., \& Axelrod, S. (1983). Punishment: a concept that is no longer necessary. Progress in Behavior Modification, 14, 355-382. doi:10.1016/b978-0-12-535614-5.50012-6. 